\title{
Re-Use of Hospital Plastic Waste in Asphalt Mixes as Partial Replacement of Coarse Aggregate
}

\author{
Syed Shahan Ali Shah1, Rawid Khan' \\ ${ }^{1}$ Iqra National University, Peshawar, Pakistan \\ ${ }^{2}$ National Institute of Urban Infrastructure Planning, University of Engineering \& Technology, \\ Peshawar, Pakistan \\ Email: syedshahaan@live.com
}

Received 22 February 2016; accepted 24 May 2016; published 27 May 2016

Copyright (C) 2016 by authors and Scientific Research Publishing Inc.

This work is licensed under the Creative Commons Attribution International License (CC BY). http://creativecommons.org/licenses/by/4.0/

(c) (i) Open Access

\begin{abstract}
About 1.3 billion tons of waste is being generated in the world annually. This waste is a cause of various diseases. Open dumping of waste also destroys valuable agricultural land. Various researchers have beneficially used plastic waste in cement concrete and asphalt concrete in the past. This study aims at the use of aggregates, made from different types of plastic waste, as partial replacement of coarse aggregates in asphalt mixes. For this purpose waste is collected from different hospitals of the city. Sorted plastic from the waste consists of $64 \%$ low density polyethene, $32 \%$ high density polyethene and $4 \%$ of polypropylene. Plastic waste is shredded, heated and after cooling, pulverizes manually and mechanically. Specific gravity of plastic aggregates is 0.96 . Water absorption and soundness values are $4.68 \%$ and $7.68 \%$ respectively. Impact, crushing and Loss Angeles values of plastic aggregates are $0.7 \%, 0.5 \%$, and $1.1 \%$ respectively. Replacement of natural aggregates by plastic aggregates in asphalt mixes is done up to $25 \%$ with $5 \%$ incremental increase. Density of asphalt mixes decreases to $2060 \mathrm{~kg} / \mathrm{m}^{3}$. Consequently flow increases to $5.73 \mathrm{~mm}$. Maximum stability is at $20 \%$ replacement i.e. $34.57 \mathrm{KN}$. Cost analysis of the study indicates that $205 \%$ increase in stability are observed with $219 \%$ increase in cost.
\end{abstract}

\section{Keywords}

Hospital Waste (HW), Plastic Waste, Waste Generation, Asphalt Stability, Plastic Aggregates

\section{Introduction}

Solid waste is the waste arising from human and animal activities that is normally solid and is discarded as use- 
less or unwanted [1]. According to World Bank Solid Waste Thematic Group, 1.3 billion tons per year of solid waste is being generated in world. This waste is likely to increase to 2.2 billion tons per year by 2025 [2]. World Health Organization (WHO) states that more than 1.5 million people die annually due to poor solid waste management. Waste poses severe hazard to public health through blocking of drainage system, formation of standing ponds, and creating breeding grounds for mosquitoes and flies. This triggers malaria and cholera. $40 \%$ of the deaths in Pakistan are due to poor waste management [3]. In addition, because of lack of proper dumping sites, most of the collected waste ends up in open pits, ponds, rivers, dumping grounds, and agricultural lands. A part of this waste gets decomposed in the environment at dumpsites but non-biodegradable waste stays there for years.

\section{Theory}

Shredded plastic waste was used in concrete as replacement of sand by Zainab Z. Ismail et al. [4]. $30 \mathrm{~kg}$ of waste plastic was recycled in the study. Tests conducted on concrete included compressive strength, flexural strength, fresh density, dry density, toughness indices, and slump. Curing ages were 3, 7, 14, and 28 days. The results indicated the production of the micro crack in concrete mixtures, but guided the reusing plastic to replace sand in cement concrete provides a decent method to unravel certain of the solid waste evils caused by plastics. Mariaenrica Frigione et al. [5] then extended the work of Zainab Z. Ismail with different W/C ratio. Samples with changed water/cement ratio and cement content were prepared. Mechanical tests at 28 and 365 days were done on the polyethylene terephthalate (PET) concretes along with on reference concretes comprising of only natural fine aggregate. It was noted that compressive strength, workability, and splitting tensile strength was lowered to some extent than that of reference concrete but ductility was reasonably higher. The importance of curing on durability was examined by V. Silva et al. [6]. Concrete mixes were prepared in which natural aggregates were substituted by PET aggregate by $0 \%, 7.5 \%$ and $15 \%$. The prepared concrete samples were exposed to laboratory environment, open-air environment, and wet chamber curing systems. Tests for water absorption by immersion, shrinkage, water absorption by capillarity action, chloride penetration were done. Results showed decrease in durability. All samples performed poorly when exposed to drier curing regimes. Nevertheless, sensitivity analyses revealed less deterioration of plastic aggregate concrete, when subjected to progressively drier curing regimes.

Sinan Hınıslığlu et al. [7] used shredded high density polythene (HDPE) as a binder replacement in asphalt. Four percent $\mathrm{HDPE}, 165^{\circ} \mathrm{C}$ of mixing temperature and 30 minutes of mixing time were determined as optimum conditions for Marshall Stability, flow and Marshall Quotient (MQ). Effect of plastic fibers in asphalt concrete was studied by Serkan Tapkın et al. [8]. Asphalt samples with polypropylenefibers were prepared. For fiber-reinforced samples, the flow values decreased and Marshall Stability values increased. An increased in the fatigue life was also observed. Fiber-reinforced asphalt mixture showed a reduced amount of reflection cracking and good resistance to prolonged fatigue life, and rutting. Wasted plastic bottles were used by Esmaeil Ahmadinia et al. as fine aggregates in asphalt [9]. Main objective of the research was to see the influence of plastic bottles in asphalt concrete. $2 \%, 4 \%, 6 \%, 8 \%$ and $10 \%$ shredded plastic bottles by weight of bitumen were added. Suitable amount of PET was established to be $6 \%$. Natural aggregates were coated with plastic and their abrasion, crushing values were calculated by Afroz Sultana et al. [10]. Various types of plastic for example Low Density Polythene (LDPE), Polypropylene, and HDPE were mixed. Modified and Unmodified asphalt binders were put into rheological test. Marshall Stability tests were also performed. Outcomes exhibited improved values for asphalt concrete. Use of polyethylene terephthalate in asphalt concrete as coarse aggregate replacement resulted in a reduction of bulk density of asphalt mixes [11].

\section{Materials and Methods}

\subsection{Plastic Collection and Aggregate Formation}

Plastic waste was collected from different hospitals of the city. For sorting and shredding of waste SS Industries and Al-Hafiz Cryptoclastic Industry in Hayatabad Industrial Estate Peshawar, Pakistan were approached. Different categories of plastic were separated from waste. $64 \%$ of the waste was LDPE, 32\% was HDPE and 4\% polypropylene. All three types of waste was shredded (Figure 1(a)), mixed together and then heated (Figure 1(b)). Semi solidform of plastic obtained was cut at regular intervals and further pulverized first manually (Figure 1(c)) then by Jaw crusher. 


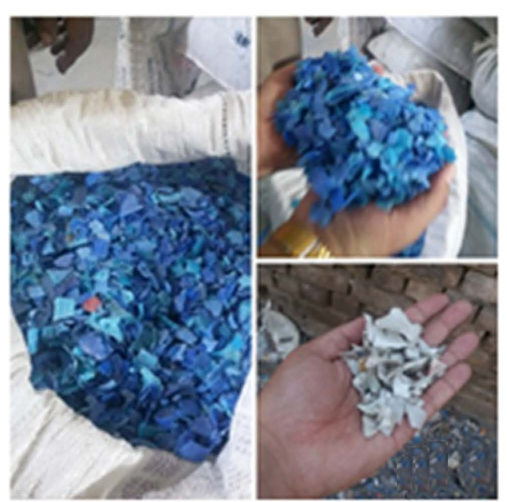

(a)

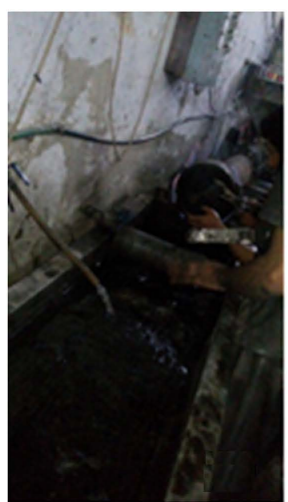

(b)

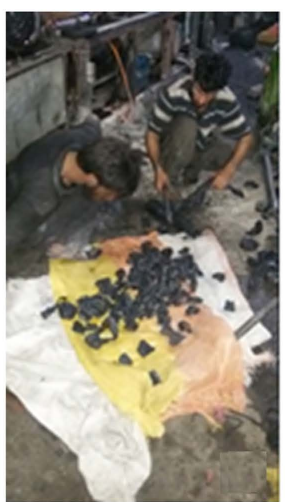

(c)

Figure 1. (a) Shredded plastic waste (b) Plastic heating pipe (c) Aggregate pulverization.

\subsection{Experimental Programme}

Following tests were performed on aggregates:

- Specific Gravity \& Water Absorption (AASHTO T 85 ASTM Designation: C 128-88)

- Aggregate Impact Value Test (BS 812-112:1990)

- Aggregate Crushing Value Test (BS 812-110:1990)

- Loss Angeles Abrasion Test (AASHTO designation: T96| ASTM C 535-12)

- Soundness of Aggregate Test (AASHTO T 104 and ASTM C 88)

- Asphalt Sample Preparation \& Testing

Natural aggregates and bitumen used in the asphalt preparations had the properties listed in Table 1 . Well graded natural aggregates were used for asphalt sampling.

Replacement of natural aggregates was done on aggregates passing 3/8 in. and retained on sieve \#4. Scheme adopted for replacement is described in Figure 2. Well graded natural aggregates were used for asphalt sample making (Figure 3(a)). Natural aggregate were replaced up to $25 \%$ (by volume) with $5 \%$ incremental increase as shown in Figure 3(b). Trial mixes were made to find the optimum binder content that came out to be $4.5 \%$.

Following tests were conducted on asphalt samples:

- Bulk Specific Gravity (AASHTO T-166-05)

- Theoretical Maximum Specific Gravity (AASHTO T-209-05)

- Marshall Stability and Flow Test

\section{Results}

\subsection{Specific Gravity and Water Absorption}

Specific gravity of plastic aggregates was less than natural aggregates. Low density of LDPE, HDPE and polypropylene was main reason for this decrease in density. Water absorption of plastic aggregates on the other hand was very high. Branched molecular structure of LDPE was the reason of this high water absorption. Figure 4(a) and Figure 4(b) show specific gravity and water absorption of plastic aggregates as compared to natural aggregates.

\subsection{Soundness Test}

Any type of polythene, whether HDPE or LDPE is generally inert to chemicals. The reason for this is lack of polarity in polythene molecules. HDPE in comparison to LDPE is more resistant to chemicals actions because of its low permeability. Low permeability comes because of high molecular weight of HDPE. Hence soundness test results for HW aggregates were low as compared to natural aggregates as shown in Figure 5.

\subsection{Aggregate Impact, Crushing and Loss Angeles Values}

As plastic aggregate impact, crushing and Loss Angeles values were less than 10, it came in "exceptionally 


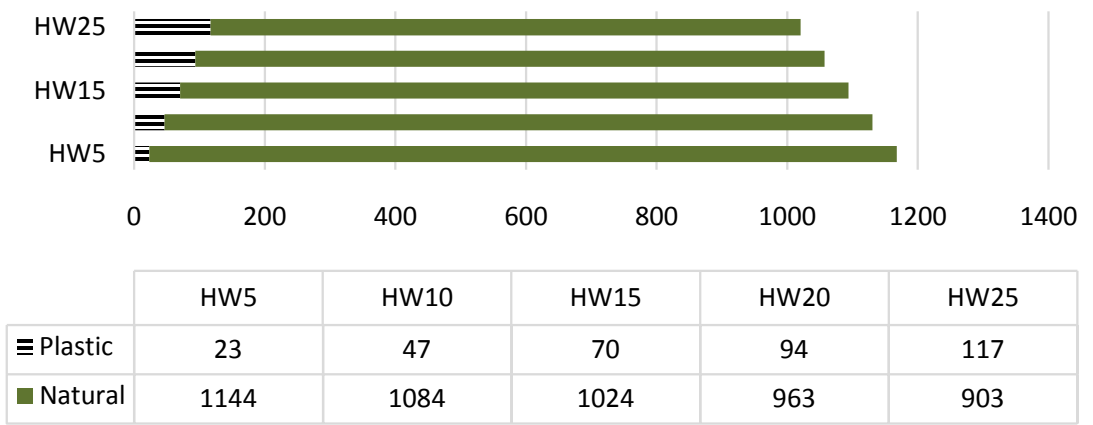

Figure 2. Mass of asphalt sample with replaced plastic aggregate.

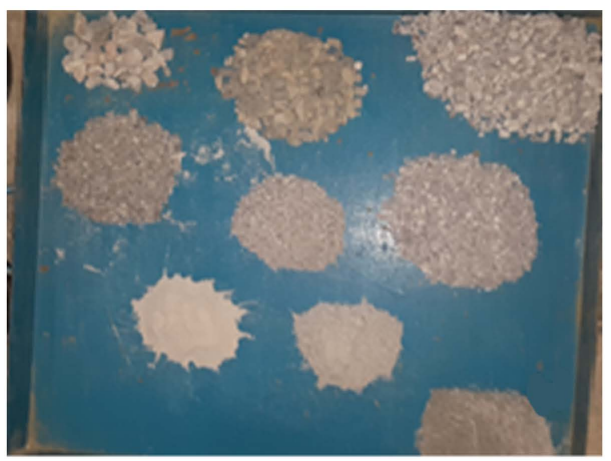

(a)

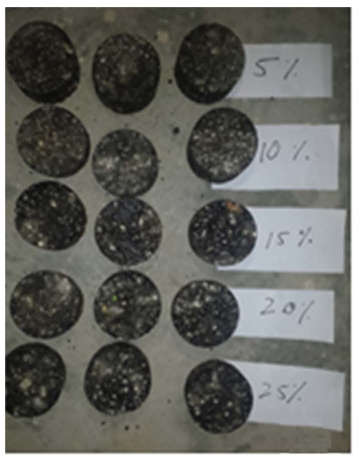

(b)

Figure 3. (a) Well graded aggregates for asphalt sample; (b) Asphalt samples.

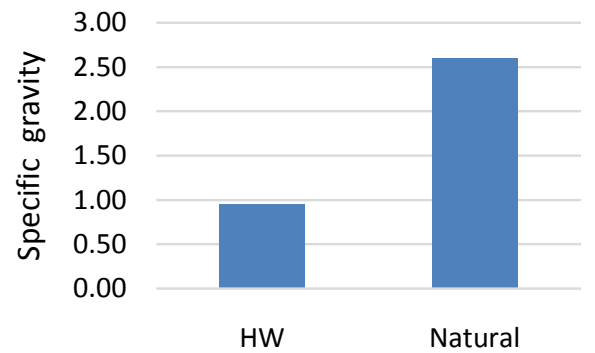

(a)

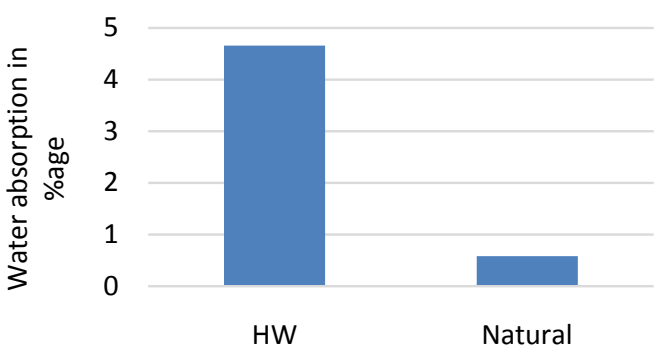

(b)

Figure 4. Specific gravity of plastic \& natural aggregates; (b) Water absorption of plastic \& natural aggregates.

Table 1. Natural aggregates and bitumen properties.

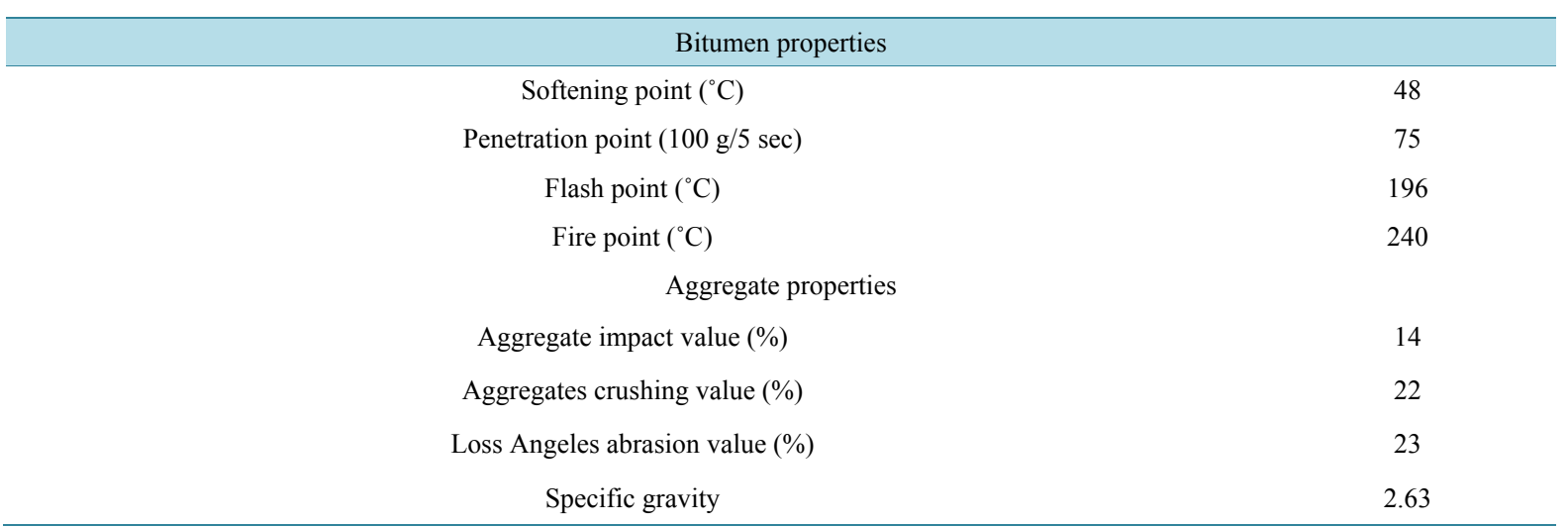




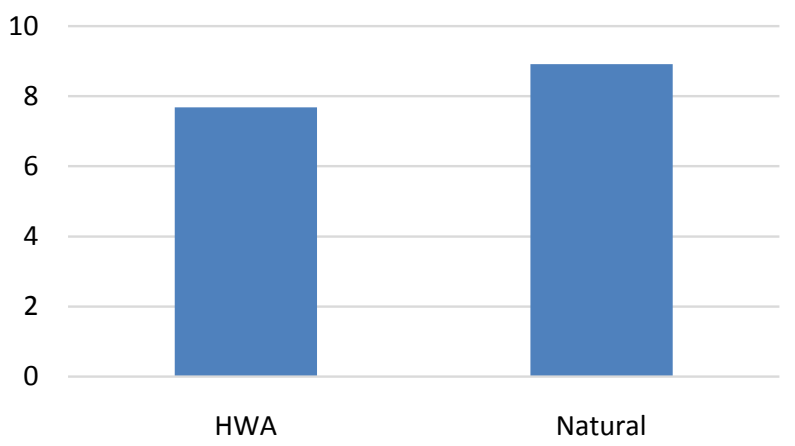

Figure 5. Soundness of aggregates.

strong" aggregate category. Major portion of HW aggregates was LDPE. This gave the aggregates more compressibility and hence lesser compression damages. Table 2 presents aggregate impact, crushing and Loss Angeles values of natural and plastic aggregates.

\subsection{Density and Percent Voids of Asphalt Samples}

Due to lesser density of plastic aggregates, asphalt samples made of replaced plastic aggregates showed lower densities with increasing plastic aggregates percentage. Figure 6(a) shows detail values of densities. As most of the bitumen was used in filling pores of plastic aggregates, less bitumen was available to fill asphalt void. This increased percent voids in asphalt mixes (Figure 6(b)).

\subsection{Stability and Flow Results}

Stability of the mixes showed increasing trend up to $20 \%$ replacement than sudden decrease in stability was observed (Figure 7(a)). This decrease in stability may be because of higher porosity of plastic aggregates. Most of the binder was used in filling the pores of plastic aggregates leaving behind insufficient quantity of bitumen to make stronger bond. As the compressibility of plastic aggregates was greater than natural aggregates, asphalt samples having plastic aggregate had higher flows (Figure 7(b)). Flow values increased with increasing plastic aggregate percentage but decreased at $25 \%$ replacement. This decrease was due to decrease in stability of mixes at $25 \%$ replacement.

\section{Cost Analysis}

Preparation cost of plastic aggregates was very high as compared to natural aggregate. The reason for this was that it was a pilot project and there was no prior manufacturing setup for making aggregates from waste plastic. Table 3 shows preparation cost of plastic aggregates. Once proper manufacturing setup has been established, preparation cost of plastic aggregates will be almost equal to that of natural aggregates. Obviously asphalt mixes made of replaced plastic aggregates were expensive than natural aggregates. Cost increased with increase in percent replacement. Table 4 shows details of cost of asphalt samples. Table 5 shows increase in stability of mixes with respective increase in cost.

\section{Conclusion}

There is no proper solid waste management system for Peshawar city. Mostly people throw the waste in their streets, where it is either picked up by scavengers or dumped there for years. In relatively developed areas of the city, scavengers collect the waste and dump it in an open area usually at a distance from densely populated area. Existing landfills of the city are not well designed. Open burning of waste on the dumpsites is observed. Major portion of the waste generated by the city is plastic. Plastic waste can be converted to aggregates by proper manufacturing setup. After performing different aggregates tests, it is found that plastic aggregates used in this research are exceptionally strong in impact, crushing and abrasion. Due to higher porosity of aggregates, soundness values are little higher. In asphalt mixes, density and percent voids increased with increasing plastic aggregates content. Stability and flow also increase with increasing plastic aggregate content. But for this increase 


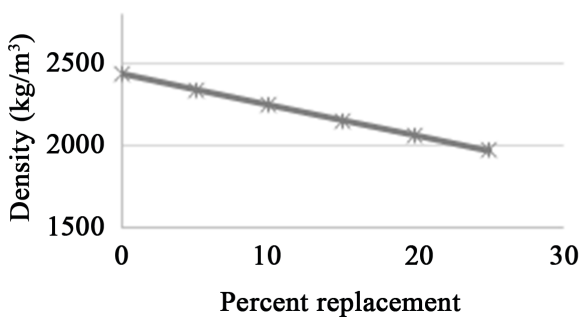

(a)

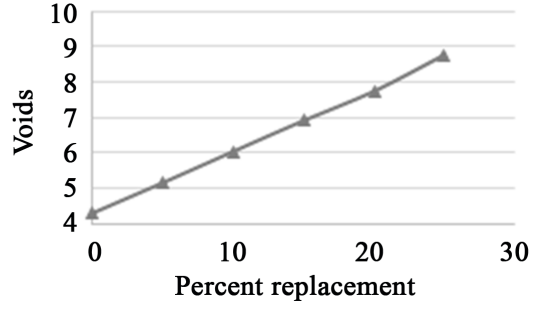

(b)

Figure 6. (a) Density of asphalt mixes; (b) Voids in asphalt samples.

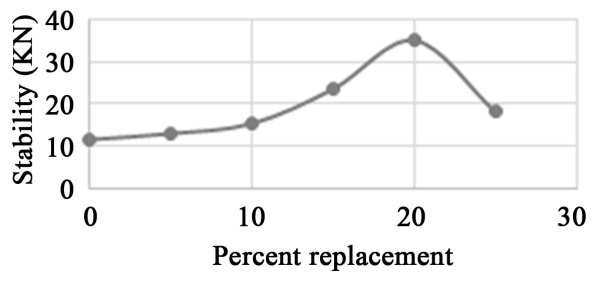

(a)

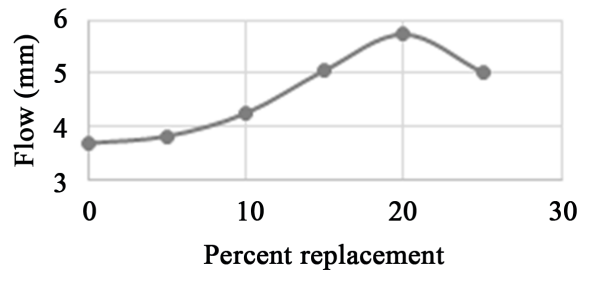

(b)

Figure 7. (a) Marshall stability of asphalt mixes; (b) Flow of asphalt mixes.

Table 2. Aggregate impact-crushing and Loss Angeles values.

\begin{tabular}{cccc}
\hline Aggregate Type & AIV & ACV & LAAS \\
\hline HWA & 0.8 & 0.5 & 1.1 \\
Natural & 14 & 22 & 23 \\
\hline
\end{tabular}

Table 3. Plastic aggregate preparation cost.

\begin{tabular}{cccccc}
\hline Process & Collection \& Transportation & Sorting & Shredding & Heating \& Pulverization & Total \\
\hline Cost $/ \mathrm{kg}(\mathrm{PKR})$ & 35 & 5 & 100 & 100 & 240 \\
\hline
\end{tabular}

Table 4. Cost of HW mixes preparation.

\begin{tabular}{|c|c|c|c|c|c|c|c|c|c|c|}
\hline \multirow{2}{*}{$\begin{array}{c}\% \\
\text { Replacement }\end{array}$} & \multicolumn{2}{|c|}{ Volume \% } & \multicolumn{2}{|c|}{ Mass } & \multicolumn{2}{|c|}{ Cost } & \multirow{2}{*}{ B. $C^{+}$} & \multirow{2}{*}{ OP.Ch ${ }^{++}$} & \multirow{2}{*}{$\begin{array}{l}\text { Total } \\
\text { Cost }\end{array}$} & \multirow{2}{*}{$\begin{array}{l}\% \text { Increase } \\
\text { in Cost }\end{array}$} \\
\hline & P.A ${ }^{*}$ & N.A ${ }^{* *}$ & P.A & N.A & P.A & N.A & & & & \\
\hline HW0 & 0 & 100 & 0 & 1200 & 0 & 3 & 4.54 & 2 & 10 & \\
\hline HW 5 & 5 & 95 & 23 & 1144 & 5.52 & 2.86 & 4.54 & 2 & 15 & 53 \\
\hline HW 10 & 10 & 90 & 47 & 1084 & 11.28 & 2.71 & 4.54 & 2 & 21 & 109 \\
\hline HW 15 & 15 & 85 & 70 & 1024 & 16.8 & 2.56 & 4.54 & 2 & 26 & 163 \\
\hline HW 20 & 20 & 80 & 94 & 963 & 22.56 & 2.41 & 4.54 & 2 & 32 & 219 \\
\hline HW 25 & 25 & 75 & 117 & 903 & 28.1 & 2.26 & 4.54 & 2 & 37 & 273 \\
\hline
\end{tabular}

"Plastic aggregate; ${ }^{* *}$ Natural aggregate; ${ }^{+}$Bitumen cost; ${ }^{++}$Operational charges.

Table 5. Increase in stability of mixes with respective increase in cost.

\begin{tabular}{|c|c|c|c|}
\hline$\%$ Replacement & $\%$ Increase in Cost $(\Delta \mathrm{C})$ & $\%$ Increase in Stability $(\Delta \mathrm{S})$ & Increase Ratio $\Delta \mathrm{S} / \Delta \mathrm{C}$ \\
\hline HW5 & 53 & 13 & 0.24 \\
\hline HW10 & 109 & 33 & 0.31 \\
\hline HW15 & 163 & 105 & 0.65 \\
\hline HW20 & 219 & 205 & 0.94 \\
\hline HW25 & 273 & 57 & 0.21 \\
\hline
\end{tabular}


in stability, cost also increases. After 25\% replacement, stability decreases while cost keeps on increasing. Therefore up to $20 \%$ of natural aggregates can be replaced by plastic aggregates.

\section{References}

[1] Vigil, S.A., Theisen, H. and Tchobanoglous, G. (1993) Integrated Solid Waste Management: Engineering Principles and Management Issues. McGraw-Hill Higher Education, USA.

[2] World Bank (2012) What a Waste. http://web.worldbank.org/WBSITE/EXTERNAL/TOPICS/EXTURBANDEVELOPMENT/0,, contentMDK:23172887 حpagePK:210058 piPK:210062 theSitePK:337178,00.html

[3] World Health organization (WHO) (2004) Analysis of Estimates of the Environmental Attributable Fraction, by Disease. http://www.who.int/quantifying_ehimpacts/publications/preventingdisease.pdf/

[4] Ismail, Z.Z. and AL-Hashmi, E.A. (2008) Use of Waste Plastic in Concrete Mixture as Aggregate Replacement. Waste Management, 28, 2041-2047.

[5] Frigione, M. (2010) Recycling of PET Bottles as Fine Aggregate in Concrete. Waste Management, 30, 1101-1106. http://dx.doi.org/10.1016/j.wasman.2010.01.030

[6] Silvaa, R.V., de Britoa, J. and Saikiab, N. (2013) Influence of Curing Conditions on the Durability-Related Performance of Concrete Made with Selected Plastic Waste Aggregates. Cement and Concrete Composites, 35, 31-35. http://dx.doi.org/10.1016/j.cemconcomp.2012.08.017

[7] Hinislioglu, S. and Karacasu, M. (2014) Use of Asphalt Plant Residue in Hot Mix Asphalt. International Journal of Global Warming, 6, 127-139.

[8] Tapkın, S. (2008) The Effect of Polypropylene Fibers on Asphalt Performance. Building and Environment, 43, 10651071. http://dx.doi.org/10.1016/j.buildenv.2007.02.011

[9] Ahmadinia, E., Zargar, M., Karim, M.R., Abdelaziz, M. and Shafigh, P. (2011) Using Waste Plastic Bottles as Additive for Stone Mastic Asphalt. Materials \& Design, 32, 4844-4849. http://dx.doi.org/10.1016/j.matdes.2011.06.016

[10] Afroz Sultana, S.K. and Prasad, K.S.B. (2012) Utilization of Waste Plastic as a Strength Modifier in Surface Course of Flexible and Rigid Pavements. International Journal of Engineering Research and Applications, 2, 1185-1191.

[11] Hassani, A., Ganjidoust, H. and Maghanaki, A.A. (2005) Use of Plastic Waste (Poly-Ethylene Terephthalate) in Asphalt Concrete Mixture as Aggregate Replacement. Waste Management \& Research, 23, 322-327. http://dx.doi.org/10.1177/0734242X05056739 